\title{
Gestão estratégica e alinhamento organizacional: estudo de caso em instituições filantrópicas de saúde do Rio Grande do Sul
}

A gestão estratégica e o alinhamento organizacional são fundamentais para as organizações que trabalham em Rede. O campo da estratégia é vasto e pressupõe as organizações em constante evolução e adaptação. Já o alinhamento para Mintzberg et al. (2006) é um ajuste necessário que deveria ocorrer entre ambiente, estratégia e recursos. O Balanced Scorecard (BSC) para Kaplan e Norton $(2004,2006)$ é uma ferramenta cada vez mais utilizada para medir o desempenho das organizações e conduz ao alinhamento entre a estratégia corporativa e as estratégias das unidades de apoio. O propósito deste trabalho é apresentar um estudo de caso sobre a gestão estratégica e alinhamento organizacional em instituiç̃os filantrópicas de saúde. Tem como objetivo analisar a estrutura de gestão estratégica da Associação Alpha e seu alinhamento junto às unidades operacionais hospitalares, com base na metodologia do Balanced Scorecard (BSC), identificando as potencialidades e fragilidades do sistema de gestão e, ao final, propor um novo modelo de gestão estratégica com vistas a uma efetiva gestão por resultados. 0 caminho metodológico percorrido pelo pesquisador quanto à natureza, classifica-se como pesquisa aplicada, quanto à abordagem, como qualitativa, quanto aos objetivos, como descritiva e exploratória; e quanto aos procedimentos técnicos, como um estudo de caso. A revisão bibliográfica está direcionada ao entendimento dos conceitos e abordagens sobres estratégias organizacionais, alinhamento estratégico, modelos de alinhamento estratégico, BSC, gestão hospitalar e cases de aplicação do BSC. Na apresentação dos resultados, identifica-se a estrutura de gestão estratégica da Associação Alpha e das unidades operacionais hospitalares, potencialidades e fragilidades do atual modelo de gestão estratégica. Por fim, propõe-se um novo modelo de gestão estratégica com vistas a uma efetiva gestão por resultados. O estudo pretende contribuir academicamente para o aprofundamento da metodologia do BSC, sobretudo em instituições hospitalares filantrópicas e, gerencialmente para a melhoria da gestão das instituições hospitalares com vistas a uma efetiva gestão por resultados.

Palavras-chave: Gestão Estratégica; Alinhamento Organizacional; Balanced Scorecard; Hospitais Filantrópicos.

\section{Strategic management and organizational alignment: case study in Rio Grande do Sul health philanthropical institutions}

\begin{abstract}
The strategic management and organizational alignment are critical for organizations who work at the Network. The field of strategy is vast and requires organizations constantly evolving and adapting. Already the alignment to Mintzberg et al. (2006) is a necessary adjustment that it should take place between environment, strategy and resources. The Balanced Scorecard (BSC) to Kaplan and Norton $(2004,2006)$ is an increasingly used tool to measure the performance of organizations and leads to alignment between corporate strategy and the strategies of support units. The purpose of this paper is to present a study case on the strategic management and organizational alignment in philanthropic health institutions. Aims to analyze the strategic support units. The purpose of this paper is to present a study case on the strategic management and organizational alignment in philanthropic health institutions. Aims to analyze the strategic
management structure of the Alpha Association and its alignment with the hospital operating units, based on the methodology of Balanced Scorecard (BSC), the potential and management system weaknesses and the end, we propose a new strategic management model with a view to effective management for results. The methodological path taken by the researcher as to the nature, is classified as applied research, on the approach, and qualitative, about the objectives, as descriptive and exploratory; and on the technical procedures, as a case study. The literature review is aimed at the understanding of the concepts and approaches about organizational strategies, strategic alignment, strategic alignment models, BSC, hospital management and the BSC application cases. The presentation of the results, identifies the strategic management structure of the Alpha Association and hospital operations, strengths and weaknesses of the current model of strategic management. Finally, it proposes a new strategic management model with a view to effective management by results. The study aims to contribute academically to the deepening of the BSC methodology, especially in philanthropic hospitals and managerially to improve the management of hospitals with a view to effective management for results.

Keywords: Strategic Management; Organizational Alignment; Balanced Scorecard; Philanthropic Hospitals.
\end{abstract}

Topic: Planejamento, Estratégia e Competitividade

Reviewed anonymously in the process of blind peer

Jocias Maier Zanatta (it)

Universidade Federal de Santa Maria, Brasi

http://lattes.cnpq.br/2721495943672931

http://orcid.org/0000-0002-9366-6500

josk85@hotmail.com

Jorge Oneide Sausen (iD)

Universidade Regional do Noroeste do Estado do Rio grande do Sul, Brasil http://lattes.cnpq.br/5913833180837421

http://orcid.org/0000-0003-3684-1410

josausen@unijui.edu.br

Ismael Alan Halberstadt

Universidade Federal de Santa Maria, Brasil

http://lattes.cnpq.br/8354968883542342

http://orcid.org/0000-0002-5418-3995

ismaah@hotmail.com

d

DOI: 10.6008/CBPC2179-684X.2019.004.0004
Received: $15 / 10 / 2019$

Approved: 21/12/2019
Referencing this:

ZANATTA, J. M.; SAUSEN, J. O.; HALBERSTADT, I. A.. Gestão estratégica e alinhamento organizacional: estudo de caso em instituições filantrópicas de saúde do Rio Grande do Sul. Revista Brasileira de Administração Científica, v.10, n.4, p.50-72, 2019. DOI: http://doi.org/10.6008/CBPC2179-684X.2019.004.0004 


\section{INTRODUÇÃO}

A gestão de organizações hospitalares é algo complexo e desafiador, que exige dos gestores eficiência e eficácia no processo de formulação e implementação de estratégias. Diante dos desafios empresariais, a adoção de ferramentas gerenciais é fundamental para uma efetiva gestão por resultados, onde o Balanced Scorecard (BSC) surge como alternativa para um sistema de avaliação de desempenho que englobe os objetivos organizacionais, a tomada de decisão e a aprendizagem organizacional.

O crescimento das organizações e o incremento do nível de complexidade tem exigido o aprimoramento dos sistemas de gestão de todas as organizações e nas organizações filantrópicas se torna um desafio (SAUSEN, 2013). No Brasil, os hospitais filantrópicos são fundamentais para o funcionamento do sistema de saúde nacional, especificamente no Sistema Único de Saúde (SUS), sendo caracterizado por não ter a finalidade de lucro, como ocorre com os demais hospitais (CUNHA et al., 2013; LIMA et al., 2007)

As instituições da área da saúde passam por dificuldades pela falta de recursos financeiros, ineficiência de gestão e descaso dos órgãos públicos. Gerenciar uma rede de hospitais é complexo e o alinhamento estratégico torna-se importante para alinhar os recursos organizacionais com as ameaças e oportunidades do ambiente (PORTER, 1992), neste contexto, é necessário que as unidades de negócio estejam alinhadas com sinergia (KAPLAN et al., 2000).

Diversos estudos tratam da aplicação e operacionalização do Balanced Scorecard em instituições de saúde no Brasil e no exterior, cita-se os seguintes hospitais: Duke Children's Hospital (CALHAU, 2009), Hospital 9 de Julho (SANTOS, 2001; CARVALHO et al., 2005), Hospital de Caridade de Carazinho (CERETTA et al., 2003).

O presente estudo tem o objetivo de analisar a estrutura de gestão estratégica da Associação Alpha e seu alinhamento junto às unidades operacionais hospitalares, com base na metodologia do BSC, identificando as potencialidades e fragilidades do sistema de gestão e, ao final, consolidar uma gestão integrada que permite uma melhor avaliação e acompanhamento do desempenho e alinhamento das unidades hospitalares pertencentes à associação, com vistas a uma efetiva gestão por resultados.

Neste estudo o nome da organização será preservado, a Mantenedora dos Hospitais será denominada 'Associação Alpha' e os Hospitais serão tratados como Hospital A, Hospital B e Hospital C. A Associação Alpha está em busca de evolução na sua forma de gestão, e iniciou um processo corporativo de trabalho em Rede, que engloba todas suas unidades operacionais hospitalares, tornando necessário um novo modelo de gestão para uma efetiva gestão por resultados, o que justifica o estudo realizado. 0 estudo tem como contribuição acadêmica o aprofundamento da metodologia do BSC, sobretudo em instituições hospitalares, e como contribuição gerencial, o suporte na gestão de unidades operacionais hospitalares filantrópicas e gerenciadas por religiosas, com vistas para uma efetiva gestão por resultados.

\section{METODOLOGIA}

Com o objetivo de contribuir com a gestão de uma instituição filantrópica de saúde e estudar o 
alinhamento estratégico entre a mantenedora e suas três unidades operacionais hospitalares e garantir a confiabilidade e o rigor científico da pesquisa, serão apresentados os procedimentos metodológicos que conduziram o processo investigatório.

\section{Classificação da pesquisa}

Minayo (2008) define a pesquisa como "a atividade básica da ciência na sua indagação e construção da realidade. É a pesquisa que alimenta a atividade de ensino e a atualiza frente à realidade do mundo". Na visão de Demo (1996), a ciência é uma atividade cotidiana, uma atitude, um posicionamento crítico ou criativo, ou ainda, uma intervenção na realidade. A ciência não é previsível, visto que, não há apenas uma única maneira de elucidar as incertezas da realidade, que envolve uma pesquisa científica.

No processo de investigação científica os métodos expressam um conjunto de procedimentos e técnicas, onde as bases de investigação são fornecidas pelos métodos, que podem ser: dedutivo, indutivo, hipotético-dialético, dialético e fenomenológico (GIL, 1999). A pesquisa científica possui o objetivo de ultrapassar o senso comum através do método científico (MINAYO, 2008).

Uma investigação nasce por uma indagação, um problema, uma dúvida e a resposta a esta investigação surge através de conhecimentos anteriores ou da criação de novos referenciais (MINAYO, 2008). Os pesquisadores dispõem de diversos meios para realizar uma investigação, que busca solucionar questões e problemas de pesquisa ou proporcionar avanços no conhecimento científico.

A classificação que está sendo apresentada na presente pesquisa se baseia nas suas principais características: quanto à natureza, classifica-se como pesquisa aplicada, quanto à abordagem, como qualitativa, quanto aos objetivos, como descritiva e exploratória; e quanto aos procedimentos técnicos, como um estudo de caso, pois trata-se de uma investigação planejada, da gestão e alinhamento estratégico, envolvendo a Associação Alpha e suas três unidades operacionais hospitalares.

Segundo Vergara (2009), a pesquisa desta natureza tem finalidade prática, ou seja, é ocasionado pelo anseio intelectual do pesquisador e a necessidade de resolução de problemas concretos. Na pesquisa aplicada, as questões de pesquisa são centradas em problemas e preocupações das pessoas, onde o propósito é gerar potenciais soluções. Esta pesquisa aplicada se refere a discussão de problemas, utilizando um referencial teórico de uma temática e a apresentação de alternativas de resolução dos problemas. A presente pesquisa é classificada como pesquisa aplicada, também por que se preocupa com um problema real, vivido por instituições hospitalares, com o propósito de gerar alternativas para a gestão e o alinhamento estratégico da rede.

No entendimento de Minayo (2008), a pesquisa qualitativa tem como foco principal a exploração do conjunto de opiniões e representações sociais sobre a temática que se pretende investigar. A pesquisa qualitativa permite conhecer o que não pode ser traduzido em números, ou seja, a dinâmica entre o mundo objetivo e subjetivo do sujeito. Durante o processo investigatório, o aspecto qualitativo se deu pela aplicação de entrevistas para coleta de dados sobre a gestão e alinhamento estratégico, com os gestores da Associação Alpha e das unidades operacionais hospitalares. O objetivo foi identificar o atual modelo de gestão e verificar 
se as estratégias das unidades operacionais hospitalares estão alinhadas com a mantenedora. A abordagem qualitativa foi necessária, à medida em que trabalhou-se a partir das percepções dos entrevistados, buscando compreender relações, atitudes, crenças e hábitos.

Quanto à classificação da pesquisa científica, o presente estudo enquadra-se no campo dos objetivos da pesquisa com caráter descritivo e exploratório. A pesquisa descritiva expõe características de determinada população ou de determinado fenômeno e pode estabelecer correlações entre variáveis e definir sua natureza (VERGARA, 2009). Os estudos descritivos exigem dos pesquisadores uma série de informações do que se vai pesquisar e têm como objetivo principal, aprofundar a descrição de determinada realidade (TRIVIÑOS, 1987). A partir desta exposição teórica, a pesquisa, classificada como descritiva, foi realizada com os diretores da instituição pesquisada e envolveu a interpretação e a percepção destes gestores quanto a gestão e o alinhamento estratégico entre a Mantenedora e as unidades operacionais hospitalares.

De acordo com Triviños (1987), "os estudos exploratórios permitem ao investigador aumentar sua experiência em torno de determinado problema". Neste sentido, a pesquisa também foi exploratória, pois investigou quais aspectos norteiam a gestão e o alinhamento estratégico das instituições estudadas. Para Triviños (1987), o estudo de caso é uma categoria de pesquisa cujo o objeto em questão é uma unidade que se analisa profundamente, guiada por duas circunstâncias: a natureza e a abrangência desta unidade. Outra definição é dada por Yin (2003), em que descreve o estudo de caso como uma investigação empírica de um fenômeno contemporâneo dentro de seu contexto de realidade.

A pesquisa é portanto, um estudo de caso e tem como objeto de análise a gestão e o alinhamento estratégico entre a Mantenedora e as unidades operacionais hospitalares, através da análise do planejamento estratégico corporativo, proposto pela Mantenedora; o planejamento aplicado pelas unidades operacionais hospitalares; e o alinhamento estratégico entre unidades e a Mantenedora, utilizando o Balanced Scorecard como sistema de alinhamento estratégico.

\section{A organização objeto de estudo}

Os objetos do estudo foram as unidades hospitalares da Associação de Literatura e Beneficência (ASLB), que foi fundada em 30 de agosto de 1932. Tem como associadas as Irmãs Filhas do Sagrado Coração de Jesus e é uma sociedade civil, de fins não econômicos, filantrópica, de caráter beneficente, educativo, cultural e de assistência social.

A Associação Alpha é composta por cinco unidades operacionais de educação, três unidades operacionais de assistência social, três unidades operacionais de saúde e inserções na comunidade, em que religiosas, através da presença solidária, auxiliam pequenas localidades com vulnerabilidade social, em diversos países do mundo. Para a pesquisa em questão, foi feito um recorte do estudo, onde foi considerado apenas a Associação Alpha e as três unidades operacionais hospitalares, sendo que cada uma delas possui equipe diretiva distinta.

Todas as unidades operacionais hospitalares possuem características de filantropia, no entanto, cada unidade possui peculiaridades que foram levadas em consideração no estudo. Abaixo a caracterização das 
unidades operacionais hospitalares que pertencem a Associação de Literatura e Beneficência, que foi o caso estudado, vide Quadro 1.

Quadro 1: Caracterização das unidades operacionais hospitalares.

\begin{tabular}{|l|l|l|}
\hline Unidade Operacional Hospitalar & Localização & Características \\
\hline Hospital 1 & $\begin{array}{l}\text { Região Metropolitana de Porto } \\
\text { Alegre - RS }\end{array}$ & Hospital Filantrópico, Especializado em Oftalmologia \\
\hline Hospital 2 & $\begin{array}{l}\text { Região Noroeste do Estado do Rio } \\
\text { Grande do Sul }\end{array}$ & $\begin{array}{l}\text { Hospital Filantrópico, Especializado em Reabilitação } \\
\text { Física }\end{array}$ \\
\hline Hospital 3 & $\begin{array}{l}\text { Região Noroeste do Estado do Rio } \\
\text { Grande do Sul }\end{array}$ & Hospital Filantrópico, Hospital geral \\
\hline
\end{tabular}

\section{Sujeitos da pesquisa}

Os dados necessários para a realização da pesquisa foram coletados com as lideranças dos níveis estratégico, tático e operacional, compreendendo diretoria, gerentes e coordenadores, da Associação Alpha e das três unidades operacionais hospitalares. Os sujeitos da pesquisa foram selecionados em função ao cargo que ocupam e o conhecimento que possuem da gestão das unidades objetos de estudo. Portanto, foram entrevistados 20 gestores conforme demonstra o resumo abaixo:

\section{Quadro 2: Gestores entrevistados}

\begin{tabular}{|l|l|l|l|l|l|}
\hline \multirow{2}{*}{ Unidade } & Nível Estratégico & Nível Tático & Nível Operacional & Total \\
\cline { 2 - 6 } & Diretor & Gerente & Coord. Assistencial & $\begin{array}{l}\text { Coord. } \\
\text { Administrativo }\end{array}$ \\
\hline Associação Alpha & 1 & 1 & 0 & 2 & 4 \\
\hline Hospital 1 & 1 & 1 & 2 & 2 & 6 \\
\hline Hospital 2 & 1 & 1 & 1 & 1 & 4 \\
\hline Hospital 3 & 1 & 1 & 2 & 2 & 20 \\
\hline \multicolumn{7}{|l|}{ Total de sujeitos } \\
\hline
\end{tabular}

\section{Coleta de dados}

Para Yin (2003), o estudo de caso "pode se basear em muitas fontes de evidências", dentre elas, entrevistas, observação direta, observação participante, registros em arquivos e documentação. A coleta de dados contempla dados primários, onde foram realizadas entrevistas semiestruturadas com os gestores da Associação Alpha; e dados secundários, através do levantamento de informações nos planejamentos estratégicos, planos táticos operacionais e instrumentos de gestão da Associação Alpha e das unidades operacionais de saúde.

A coleta de dados deste estudo compreendeu a pesquisa bibliográfica, pesquisa documental e pesquisa de campo: a) Pesquisa bibliográfica em livros, artigos publicados e teses com dados relativos à temática do alinhamento estratégico; b) Pesquisa documental nos arquivos impressos e digitais relacionados ao planejamento estratégico das organizações objeto de estudo; c) Pesquisa de campo, por meio de questionários e entrevistas semiestruturadas.

A pesquisa bibliográfica iniciou durante a elaboração do projeto e foi concluída durante a realização da dissertação, sendo revisada sempre que necessário. A realização das entrevistas com os diretores da Associação Alpha e das unidades operacionais hospitalares aconteceu na sede onde elas estão localizadas, mediante prévio agendamento e deslocamento realizado antecipadamente. As entrevistas foram realizadas 
com o auxílio de um roteiro pré-determinado, gravação digital do diálogo e bloco de anotações, para registrar as observações do pesquisador.

A pesquisa documental do planejamento estratégico aconteceu em sintonia com a realização das entrevistas e também por meio eletrônico (e-mail) quando necessário. Nesta etapa foram verificadas todas as informações relativas à gestão e alinhamento estratégico entre a Associação Alpha e as unidades operacionais hospitalares.

Foi realizado um questionário semiestruturado a partir de trabalhos realizados sobre a temática, com questões objetivas e questões abertas a partir de um roteiro de perguntas previamente elaboradas em relação ao sistema de gestão da rede, alinhamento das unidades operacionais hospitalares e controle e avaliação do planejamento.

\section{Análise de dados}

De acordo com os objetivos propostos para esta pesquisa, os dados foram levantados por meio de entrevistas semiestruturadas e análise documental. Através destas técnicas, foi identificado a forma de gestão e alinhamento estratégico entre a Associação Alpha e as unidades operacionais hospitalares, levando em consideração a documentação do planejamento estratégico corporativo e das unidades, possibilitando identificar o nível de alinhamento estratégico entre ambos.

Também foram estabelecidas relações com a fundamentação teórica, para não limitar a análise somente ao olhar do pesquisador. A fase de coleta e análise dos dados muitas vezes ocorreram de maneira simultânea em determinadas etapas da pesquisa. A análise foi realizada mediante a constatação da atual forma de gestão e alinhamento estratégico, concomitante com a comparação ao referencial teórico abordado no trabalho e identificação das potencialidades e fragilidades do atual sistema.

Para a análise e interpretação dos dados foi elaborada uma matriz contendo as informações da gestão estratégica das Instituições objeto de pesquisa, mediante a análise do planejamento estratégico da Mantenedora e de cada unidade operacional hospitalar. Após elaborar a síntese destas informações, foi possível verificar se a gestão estratégica de cada unidade está alinhada às estratégias da Mantenedora, utilizando como filtro o Balanced Scorecard. A análise dos dados foi elaborada procurando evidenciar as potencialidade e fragilidades do sistema de gestão da organização a partir da comparação da atual estrutura de gestão, comparada com os pressupostos encontrados na literatura sobre planejamento estratégico e sistema de alinhamento estratégico, consubstanciado no BSC (KAPLAN et al., 2006).

\section{Estratégias organizacionais}

No meio empresarial o conceito de estratégia se popularizou a partir da década de 60 , de forma associada ao planejamento estratégico. A partir deste momento, iniciou-se efetivamente a prática de olhar para o futuro e definir objetivos para as organizações, em um contexto de mudanças, que exige reposicionamentos constantes na gestão das organizações (SAUSEN, 2012). Entende-se, que em se tratando de estratégia, existem numerosas definições e conceitos distintos, havendo consenso de que a utilização de 
estratégias é uma atividade de conteúdo e de processo variável, onde é possível aplicar vários modelos, que podem favorecer ou não o sucesso de uma administração (BETHLEM, 2001).

A perspectiva estratégica supõe as organizações em evolução, alcançando novos resultados como fruto de sua capacidade de adaptação ao meio e de inovação, sendo a decisão estratégica resultado de um processo social, técnico e político, parcialmente controlável, por suas características racionais e ilógicas ao mesmo tempo (MOTTA, 2001b).

Para Ansoff et al. (1993), estratégia é um conjunto de regras de tomada de decisão para orientação do comportamento de uma organização, tendo quatro tipos distintos de regras: a) Padrões de desempenho ou objetivos e metas; b) Regras para o desenvolvimento das relações com o ambiente externo ou estratégia empresarial; c) Regras para o estabelecimento das relações e processos internos ou conceito organizacional; d) Regras para a condução do trabalho diário ou políticas operacionais.

Mintzberg et al. (2010) reuniram diferentes olhares e agruparam em escolas do pensamento de estratégia, que exploram os estudos da estratégia pela natureza prescritiva e descritiva do processo de formulação de estratégias. No Quadro 1 são apresentadas as dez escolas do pensamento estratégico de Mintzberg.

Quadro 3: Gestores entrevistados.

\begin{tabular}{|c|c|c|}
\hline Escola & $\begin{array}{l}\text { Descrição da } \\
\text { formulação de } \\
\text { estratégia }\end{array}$ & Principais autores \\
\hline Design & $\begin{array}{l}\text { Como um processo de } \\
\text { concepção }\end{array}$ & Selznick; Grupo de Harvard: Christensen et al Kenneth Andrews \\
\hline Planejamento & $\begin{array}{l}\text { Como um processo } \\
\text { formal }\end{array}$ & Ansoff; Steiner ; Schendel e Hofel ; Lorange \\
\hline Posicionamento & $\begin{array}{l}\text { Como um processo } \\
\text { analítico }\end{array}$ & Von Clausewitz ; Liddell-Hart; Katz ; Hunt; Henderson; Porter \\
\hline Empreendedora & $\begin{array}{l}\text { Como um processo } \\
\text { visionário }\end{array}$ & $\begin{array}{l}\text { Schumpeter; Cole; McClelland; Knight; Drucker; Collins e Moore; Mintzberg; } \\
\text { Pinchot; Stevenson e Gumpert; Palich e Bagby }\end{array}$ \\
\hline Cognitiva & $\begin{array}{l}\text { Como um processo } \\
\text { mental }\end{array}$ & Simon; Smitich e Subbart; Ann Huff; Córner, Kinicki e Keats \\
\hline Aprendizado & $\begin{array}{l}\text { Como um processo } \\
\text { emergente }\end{array}$ & $\begin{array}{l}\text { Lindblom; Cyert e March; Karl Weick; Bower; Argyris; Normann; Quinn; Nelson e } \\
\text { Winter; Schön; Burgelman; Hardy et al.; Senge; Prahalad e Hamel; Noda e Bower; } \\
\text { Crossan, Lane e White }\end{array}$ \\
\hline Poder & $\begin{array}{l}\text { Como um processo de } \\
\text { negociação }\end{array}$ & $\begin{array}{l}\text { MacMillan; Sarrazin; Pettigrew; Zald e Berger; Pfeffer e Salancik; Bower e Davis; } \\
\text { Freeman; MacMillan e Guth; Bolman e Deal }\end{array}$ \\
\hline Cultural & $\begin{array}{l}\text { Como um processo } \\
\text { coletivo }\end{array}$ & $\begin{array}{l}\text { Rhenman; Normann; Hedberg e Honsson; Schwartz e Davis; Wernerfelt; } \\
\text { Pettigrew; Firsirotu; Feldman; Barney; Rieger; Barney; Roth e Ricks }\end{array}$ \\
\hline Ambiental & $\begin{array}{l}\text { Como um processo } \\
\text { reativo }\end{array}$ & Pugh et al.; Hannan e Freeman; Miller; Mintzberg; Droge e Toulouse; Oliver \\
\hline Configuração & $\begin{array}{l}\text { Como um processo de } \\
\text { transformação }\end{array}$ & Darwin; Chandler; Miller; Mintzberg; Miller e Friesen; Hurst \\
\hline
\end{tabular}

Fonte: Adaptado de Mintzberg et al. (2010).

No entendimento de Whittington (2002), temos quatro abordagens genéricas acerca dos estudos sobre estratégias, que diferenciam-se pelas dimensões de resultados e processos: abordagem clássica, abordagem evolucionária, abordagem processualista e a abordagem sistêmica, conforme se observa na Figura 1. 


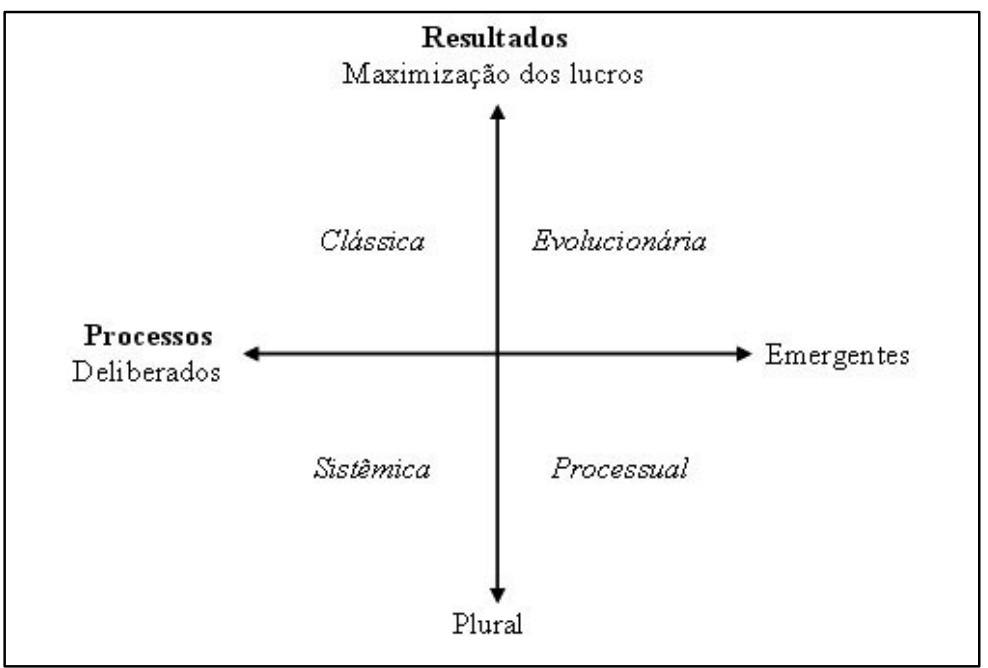

Figura 1: Perspectivas genéricas sobre estratégia. Fonte: Whittington (2002).

Para a abordagem clássica, o lucro é o objetivo principal e a forma de alcançar este objetivo é através do planejamento racional. Esta abordagem em relação a estratégia de negócios é algo recente, surgindo trabalho consistente em 1960, com Chandler (1962) e Igor Ansoff (1965). As principais características da abordagem clássica são: análise racional, distanciamento entre concepção e execução e maximização dos lucros.

$\mathrm{Na}$ abordagem evolucionária são os mercados e não os gestores, que escolhem as estratégias predominantes no ambiente. De acordo com Whittington (2002), algumas características ficam visíveis na abordagem evolucionária: foco na eficiência relativa, concentração nos custos de transação, coordenação e organização, abundância de iniciativas inovadoras e perfeição dos mercados competitivos. $\mathrm{O}$ autor ainda ressalta que para esta abordagem, a sobrevivência da empresa no ambiente estaria relacionada com a diferenciação.

A abordagem processual orienta para aceitar o mundo como ele é, ao invés de buscar um ideal de uma ação racional. A análise da complexidade interna das organizações resultou em dois princípios fundamentais para o pensamento processualista: os limites cognitivos de ação racional, expandido por Henry Mintzberg (1987) e a micropolítica das organizações, trabalhada por Andrew Pettigrew $(1973,1985)$.

As pessoas são limitadamente racionais, sendo parciais em suas interpretações de dados, de modo a aceitar uma opinião satisfatória. A visão micropolítica nas organizações visualiza uma barganha interna, onde não é possível ter o lucro como objetivo comum. Para Whittington (2002), "a perspectiva processual diminui radicalmente a importância da análise racional, limita a busca pela flexibilidade estratégica e reduz as expectativas de sucesso".

A teoria sistêmica parte do princípio de que os gestores responsáveis pela tomada de decisão, não são puramente indivíduos imparciais, calculistas, atrelados apenas a ações econômicas, mas são indivíduos com raízes, em que as empresas se diferem de acordo com os sistemas sociais e econômicos ao qual fazem parte. Esta abordagem enfatiza que as metas e processos estratégicos são influenciadas pelos sistemas sociais em que a estratégia está sendo formulada (WHITTINGTON, 2002).

As estratégias eficazes contêm três elementos essenciais: metas ou objetivos a serem atingidas; as 
políticas, que orientam a ação; e os programas, que levarão ao cumprimento das metas estabelecidas (MINTZBERG et al., 2006). As organizações atuam em ambientes dinâmicos, nesse sentido, os estudos do processo de adaptação estratégica tem apresentado destaque pelos estudiosos das organizações (CARVALHO et al., 2011).

Os estudiosos do processo de adaptação estratégica tem direcionado as discussões em dois principais aspectos: (a) visão determinista, que defende que o ambiente é o elemento principal para a definição das estratégias organizacionais e, (b) visão voluntarista, também denominada escolha estratégica, que define as organizações como possuidoras de capacidade de manipular o ambiente, devido a suas competências materiais e organizacionais (CARVALHO et al., 2011).

Hrebiniak et al. (1985) consideram a adaptação como um processo dinâmico resultante da força e tipo de poder ou dependência entre a organização e o ambiente. Os autores desenvolveram uma matriz de determinismo e escolha estratégica, onde propõe que a estratégia e o determinismo são variáveis independentes, e sua interação tem o objetivo de desenvolver a tipologia de adaptação organizacional, conforme se verifica na Figura 2.

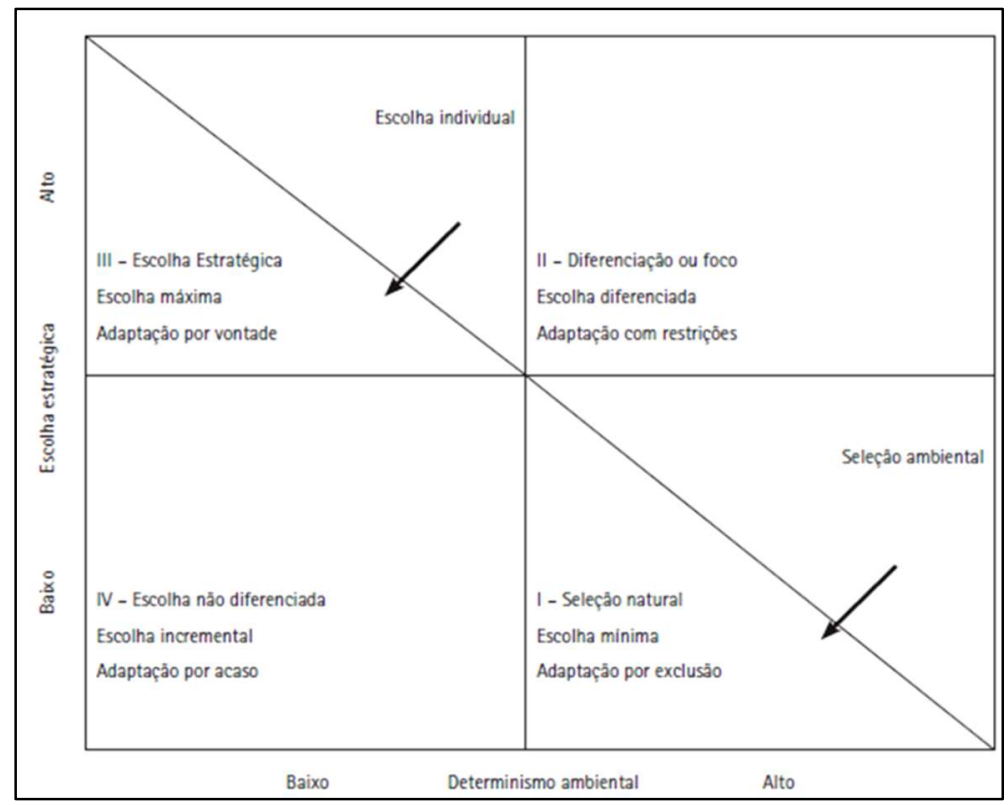

Figura 2: Perspectivas genéricas sobre estratégia. Fonte: Hrebiniak et al. (1985).

No primeiro quadrante tem escolha estratégica baixa e alto determinismo, onde o preço é determinado pelo mercado e a demanda é perfeitamente elástica, exemplificando, são empresas em ambiente de concorrência perfeita com ação gerencial restrita. Já o segundo quadrante, apresenta escolha estratégica e determinismo ambiental alto, são organizações em nichos com regras, restrições ou condições imutáveis do meio, que restringem resultados ou comportamentos, permitindo escolhas alternativas.

O terceiro quadrante tem escolha estratégica alta e determinismo baixo, e a escolha estratégica determina o domínio organizacional, sendo a autonomia e controle regra e não a exceção. No último quadrante, de escolha estratégica e determinismo ambiental baixo, são organizações que não são protagonistas, e possuem forças e competências inapropriadas às oportunidades e as condições externas, por vezes, tendo adaptação por acaso. 


\section{Alinhamento estratégico organizacional}

$\mathrm{Na}$ busca por melhores desempenhos, as organizações encontram dificuldades e muitas vezes fracassam na execução das estratégias, neste contexto o alinhamento estratégico aparece como conceito fundamental para implementação das estratégias (PESSOA et al., 2011). A conceituação de alinhamento, em relação a temática de estratégias organizacionais, ainda não esgotou as possibilidades de discussão na literatura, no entanto, de modo geral, reporta-se a ajustes entre elementos organizacionais ou ambientais, característicos de sistemas abertos em um ambiente competitivo (BARROS, 2007).

Para Mintzberg et al. (2006) o alinhamento é um ajustamento necessário que deveria ocorrer entre ambiente, estratégia e recursos. Porter (1999) considera que o alinhamento exige dos gestores um entendimento das metas e objetivos, bem como a capacidade de adquirir utilizar recursos necessários para manter a organização competitiva. $\mathrm{O}$ alinhamento estratégico perpassa pela liderança executiva (KAPLAN et al., 2006) e para as organizações manterem-se competitivas realizam ajustes estratégicos (SENFF et al., 2014).

O conceito de alinhamento estratégico norteia-se em duas suposições: a primeira converge o desempenho econômico da organização com a habilidade dos gestores em realizar os ajustes necessários entre a estratégia e sua execução; a segunda que o ajuste estratégico é dinâmico. Por isso, o alinhamento estratégico não ocorre de forma isolada, é um processo contínuo de adaptação e mudança (HENDERSON et al., 1993). Miles et al. (1984), corroboram ao comentar que o alinhamento estratégico, como processo ou resultado, é uma dinâmica que busca ajustar a organização com o seu ambiente, onde internamente busca organizar os recursos para dar suporte ao alinhamento.

No entendimento de Prieto et al. (2004) existe um consenso de que alguns elementos, como a missão, visão, cultura e objetivos, melhoram a performance organizacional. Stepannovich e Mueller (2002) propõe o alinhamento através de três modelos: alinhamento externo, alinhamento interno e consenso.

No alinhamento externo é tratado sobre as diretrizes da organização e a utilização dos recursos no local em que está inserida (SENFF et al., 2014). A análise SWOT, a análise da cadeia de valor (PORTER et al., 1985) e a análise das forças competitivas (PORTER, 1979), são algumas das ferramentas para a criação e sustentação de vantagens competitivas.

Em relação a estratégia adotada, no que diz respeito aos recursos internos, o direcionamento é dado pelo alinhamento interno. Labovitz et al. (1997) considera o alinhamento nas dimensões vertical e horizontal, e Kaplan et al. (1992) sugerem o balanced scorecard como possibilidade de alinhamento através das perspectivas do negócio.

Para que as organizações mantenham um crescimento e lucratividade de forma sustentável, deve-se ter a capacidade de concentrar esforços no foco do negócio e agir de forma alinhada (LABOVITZ et al., 1997). O BSC proporciona um alinhamento interno, onde segundo os estudos de Kaplan et al. (2000), traduz a missão e a estratégia da organização em objetivos e metas mensuráveis.

Já no alinhamento por consenso, é tratado sobre o grau de alinhamento dos funcionários da organização em relação às estratégias adotadas, desencadeando uma melhor performance organizacional 
(STEPANNOVICH et al., 2002). Kaplan et al. (2000), afirmam que diversas organizações compartilham processos de negócio comuns e utilizam a função corporativa para garantir seu uso eficaz. Grande parte das organizações possui diversas unidades de negócios distintas e unidades de serviço de apoio compartilhados, nesse contexto, para as estratégias serem eficazes é necessário que as unidades de negócio estejam alinhadas e conectadas com sinergia (KAPLAN et al., 2000).

\section{Balanced scorecard (BSC) como sistema de alinhamento estratégico - modelo de análise para o estudo}

Para Kaplan et al. (2006), o alinhamento não é um evento que ocorre e se consuma repentinamente, a implementação de um Balanced Scorecard alinha a estratégia corporativa com as estratégias das unidades de apoio. A sequência do alinhamento estratégico inicia quando a administração corporativa define a proposta de valor da organização, para criar sinergias entre as unidades operacionais, as unidades de apoio e os parceiros externos. Neste sentido, o mapa estratégico e o BSC corporativo identificam e esclarecem as prioridades da organização e as comunicam a todas as unidades de negócio e unidades de apoio (KAPLAN et al., 2006).

Os sistemas de avaliação do desempenho organizacional, tradicionalmente restringem-se à análise financeira, através de indicadores de contabilidade, pois a única preocupação dos administradores era ampliar o lucro das organizações. Neste aspecto o Balanced Scorecard possui vantagens como método de avaliação de desempenho (COELHO, 2008; LIMA et al., 2011; MACHADO, 2013). A estratégia não deve ser um processo isolado, é um processo contínuo e amplo, que começa com a missão da organização e seu desdobramento nas ações individuais (KAPLAN et al., 2000).

Para Bethlem (2001), “o Balanced Scorecard propõe-se a medir a atuação de uma empresa decorrente de suas estratégias". Neste sentido, o Balanced Scorecard é um instrumento de gestão capaz de fomentar o alinhamento estratégico, a partir de quatro perspectivas distintas: financeira, clientes, processos internos e aprendizado e crescimento (FLORES et al., 2008).

O Balanced Scorecard busca desenvolver um sistema de avaliação de desempenho que englobe os objetivos organizacionais, a tomada de decisão e a aprendizagem organizacional. Desta forma, o termo balanced enfatiza o equilíbrio entre os objetivos, medidas financeiras e não financeiras, indicadores e perspectivas de gestão, enquanto o termo scorecard ressalta a forma de demonstrar os resultados (FILGUEIRAS et al., 2010).

O Balanced Scorecard trabalha com quatro perspectivas para auxiliar as organizações na gestão do negócio, são elas: Perspectiva Financeira, Perspectiva do Cliente, Perspectiva dos Processos Internos e Perspectiva do Aprendizado e Crescimento. As medidas de desempenho agrupadas nas quatro perspectivas favorecem a visualização e o entendimento das estratégias (MENEZES et al., 2006). O BSC coloca no centro do processo gerencial a visão (para onde queremos ir) e a estratégia (como iremos), para tanto, estabelece objetivos e metas para que os colaboradores possam desempenhar suas atividades com vistas a atingir os objetivos de cada uma das quatro perspectivas (ALLEVATO, 2007). A Figura 3 demonstra as quatro perspectivas do BSC e sua inter-relação: 


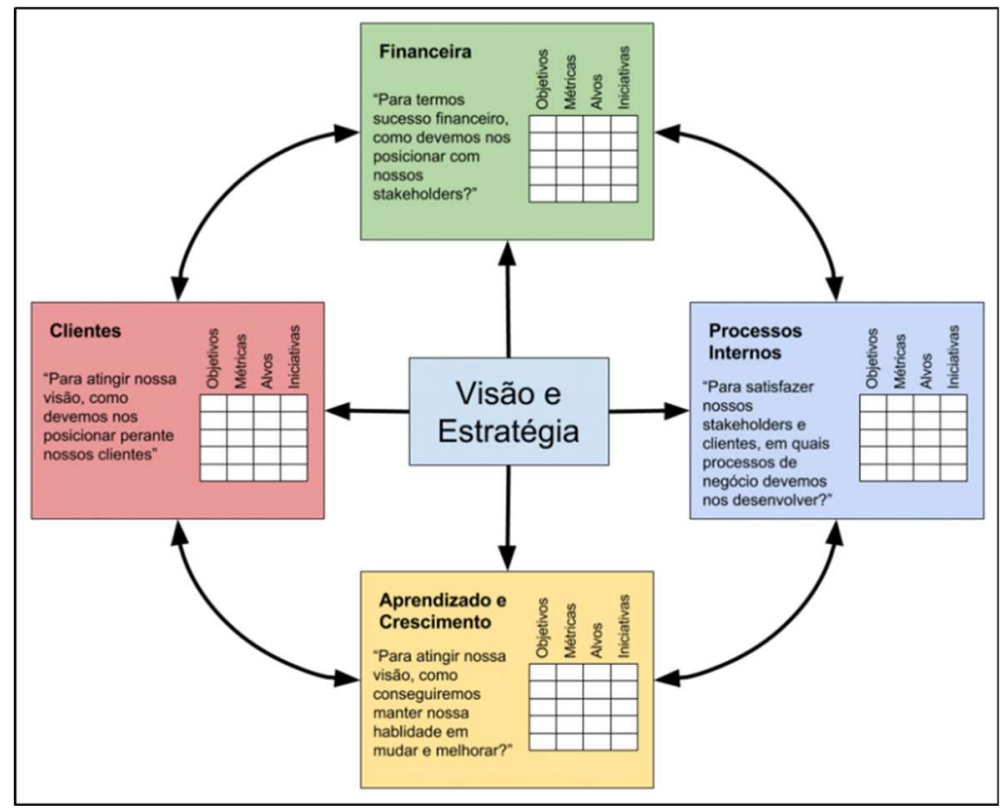

Figura 3: Perspectivas do BSC. Fonte: Kaplan et al. (1997).

\section{RESULTADOS E DISCUSSÃO}

Neste capitulo é descrito a estrutura de gestão estratégica da Associação Alpha e de suas Unidades Operacionais Hospitalares, que compreende a concepção do modelo de gestão, alinhamento organizacional e, acompanhamento e avaliação. Também, são evidenciadas as potencialidade e fragilidades do atual modelo de gestão e elaborada proposta de modelo de gestão com vistas a efetiva gestão por resultados.

\section{A estrutura de gestão estratégica da associação ALPHA}

\section{Da concepção do modelo de gestão}

No ano de dois mil e quatorze a ASLB deu início ao processo de governança corporativa, tendo como objetivo melhorar e profissionalizar os seus processos de gestão. Para tanto, foi criado um conselho de administração para gerenciar toda a rede, contemplando a assistência social, educação e saúde. Inicialmente foi realizado um projeto piloto na sede da ASLB para posteriormente avançar para as demais unidades operacionais.

O conselho de administração é composto por sete pessoas, sendo, duas sócias ${ }^{1}$, a presidente da associação, diretora financeira, diretora administrativa e dois conselheiros independentes. Todos os participantes do conselho de administração são religiosas, exceto os conselheiros independentes, os quais são contratados e com expertise nas áreas de educação e saúde.

A instituição trabalha com a ferramenta do planejamento estratégico desde o ano de mil novecentos e noventa e oito, tendo evoluído de maneira sistemática. A Associação Alpha, elabora um planejamento estratégico corporativo, e a partir dele, as unidades operacionais dos segmentos da assistência social, educação e saúde, elaboram os seus planos observando suas particularidades.

\footnotetext{
${ }^{1}$ São consideradas sócias, as religiosas, que no conselho de Administração da Associação Alpha são as representantes legais da instituição em sua forma jurídica.
} 
As diretrizes do planejamento estratégico corporativo que são disponibilizadas às unidades operacionais para elaboração de seu planejamento estratégico estão de acordo com as políticas organizacionais da Associação Alpha e de certa forma existe uma flexibilidade para sua aplicação.

Em fragmentos das respostas da diretora administrativa da Associação Alpha identifica-se as principais característica da elaboração do planejamento estratégico corporativo e como deve ser aplicado nas unidades operacionais:

DIRETORA ADMINISTRATIVA - ASSOCIAÇÃO ALPHA - "Todas as unidades elaboram o seu planejamento estratégico, mas elaboram a partir do corporativo, que é o planejamento estratégico da ASLB como um todo, recebem as diretrizes que são trabalhadas de forma flexível, e estão lincadas as políticas organizacionais, e quem elabora essas diretrizes é o conselho de administração".

A elaboração das diretrizes organizacionais e do planejamento estratégico da Associação Alpha é de responsabilidade do conselho de administração, o planejamento vigente é a longo prazo, com prazo até dois mil e vinte e três, onde anualmente é realizada reunião de revisão deste planejamento, onde são avaliados os indicadores e metas.

Todas as unidades operacionais participam da concepção do planejamento estratégico, inclusive as unidades operacionais hospitalares, no entanto esta participação se dá através dos conselheiros independentes que possuem conhecimento nas áreas da educação e saúde. Esta forma de trabalho não leva em consideração as particularidades de cada unidade operacional hospitalar, pois os conselheiros não tem conhecimento do contexto operacional destas unidades. Nas respostas dos diretores da Associação Alpha observa-se as lacunas referentes a participação das unidades operacionais hospitalares na elaboração e concepção do planejamento estratégico corporativo:

DIRETORA ADMINISTRATIVA - ASSOCIAÇÃO ALPHA - "quando pensamos no conselho de administração, foi pensado, dentro de cada expertise, conselheiros independentes que ajudam a pensar o todo e as unidades operacionais".

DIRETORA FINANCEIRA - ASSOCIAÇÃO ALPHA- "No conselho de administração os conselheiros externos possuem conhecimento técnico na área de educação e saúde e auxiliam na elaboração das diretrizes corporativas".

Todas as unidades operacionais participam da concepção do planejamento estratégico, inclusive as unidades operacionais hospitalares, no entanto esta participação se dá através dos conselheiros independentes que possuem conhecimento nas áreas da educação e saúde. Esta forma de trabalho não leva em consideração as particularidades de cada unidade operacional hospitalar, pois os conselheiros não tem conhecimento do contexto operacional destas unidades.

O planejamento estratégico é comunicado às unidades operacionais hospitalares através do compartilhamento destas informações com os diretores, através de uma reunião na sede da Associação Alpha. Neste momento é compartilhado o planejamento estratégico e as diretrizes organizacionais, para a partir disto, cada unidade operacional hospitalar elaborar seu planejamento estratégico.

A Associação Alpha iniciou em dois mil e quinze a trabalhar o processo de gestão do conhecimento, onde é utilizada a metodologia do espiral de ideias. Nesta metodologia, são chamadas as unidades operacionais hospitalares para compartilhar o que foi elaborado, seguido por um momento de externalização 
onde é alinhada a teoria e a prática, após cada unidade operacional é convidada a olhar para suas fraquezas e ameaças, elaborar planos de ação, compartilhar novamente com o grupo de gestão da Associação Alpha e após, disseminar nas unidades hospitalares operacionais.

O atual modelo de planejamento estratégico enfrenta dificuldades em sua implantação, principalmente nos aspectos da gestão do conhecimento, onde as pessoas que participam do processo não estão apropriadas dos processos, ferramentas de gestão e tem dificuldade de dar continuidade às atividades. A maior dificuldade está na área assistencial, que não tem o conhecimento como um todo, pois tem o foco na operação ao invés de foco na gestão e processos.

O planejamento estratégico deve ser elaborado pela unidade operacional hospitalar e a partir dele realizado o orçamento anual para a respectiva unidade operacional. Esta orientação da Associação Alpha não é seguida rigorosamente pelas unidades operacionais hospitalares, que tem dificuldades em executar o orçamento a partir das ações do planejamento estratégico, tendo divergências entre o orçado e realizado, onde o orçamento é apenas uma formalidade. Na resposta da diretora administrativa da Associação Alpha fica evidenciado as lacunas referentes a integração entre o planejamento estratégico e o orçamento das unidades operacionais hospitalares:

DIRETORA ADMINISTRATIVA - ASSOCIAÇÃO ALPHA - “O convite sempre é que se faça o planejamento estratégico e a partir do planejamento estratégico se faça o orçamento, que sejam duas peças que caminhem juntas, mas tem uma dificuldade ai também, o pessoal faz o planejamento e faz o planejamento sem casar os dois".

O orçamento deve ser acompanhado mensalmente, de acordo com as diretrizes da Associação Alpha, no entanto muitas vezes o processo não é seguido da forma correta, embora o planejamento seja uma proposta flexível. No decorrer da gestão do negócio ocorrem acontecimentos imprevisíveis, onde o orçamento deve ser avaliado para cada situação, com o objetivo de autorizar o desembolso de recursos não previstos e aprovados anteriormente.

Um exemplo é a crescente evolução da crise na saúde, onde afeta as instituições deste segmento diretamente no pilar financeiro, prejudicando a sustentabilidade do negócio, fazendo com que o planejamento tenha de ser revisto e realinhado frente a estas dificuldades. Esta revisão, por sua vez, muitas vezes ocorre em descompasso ao tempo necessário de reação, o que impacta diretamente na qualidade dos serviços prestados, principalmente no que está relacionado à investimentos. Quando a mantenedora ou uma unidade operacional hospitalar é impactada por alguma dificuldade é possível rodar o ciclo PDCA e reavaliar o planejamento para o enfrentamento do problema.

A atual estrutura de gestão da Associação Alpha veio para organizar o processo gerencial, no entanto, diante da complexidade, o sistema se torna robusto e por vezes engessado. As unidades operacionais hospitalares há alguns anos passaram por uma transformação em sua gestão, com a expansão das atividades e reorganização do organograma, recentemente, frente a crise da área da saúde, que atingiu fortemente os hospitais filantrópicos, fez-se necessário um enxugamento da estrutura de gestão, que adequou-se à nova realidade, o que demonstra a flexibilidade da estrutura de gestão, o que no entanto, não significa, que as decisões sejam rápidas e proativas. 


\section{Do alinhamento organizacional}

No entendimento dos gestores da Associação Alpha, existe o alinhamento entre o planejamento estratégico da mantenedora e o das unidades operacionais hospitalares. O planejamento da Associação Alpha está alinhado com todas as áreas de atuação da entidade, seguindo as diretrizes especificas para a área da saúde, educação e assistência social, sendo algumas delas comuns e outras específicas para cada área de atuação.

Dentro das unidades operacionais, em todas as áreas de atuação da mantenedora, participam da elaboração do planejamento estratégico a equipe diretiva, que é composta pela diretora geral, diretor executivo e diretora financeira, que na sequência disseminam o planejamento para as gerências e coordenações, que por sua vez, mobilizam os demais colaboradores.

As unidades operacionais recebem anualmente, com antecedência, as diretrizes impostas pela mantenedora para a revisão do planejamento estratégico, o alinhamento organizacional se dá através de reunião anual, na sede da mantenedora, geralmente no mês de novembro, onde é apresentado e discutido o planejamento estratégico de cada unidade operacional, elaborado com base nas diretrizes estratégicas da mantenedora.

O planejamento estratégico da mantenedora comtempla mecanismos de alinhamento do estratégico com o plano tático e operacional, que segundo a diretora administrativa da Associação Alpha é necessário, onde o plano estratégico é mais amplo, sendo reduzido ao tático e operacional, através do desdobramento dos planos de ação. Desta forma, os objetivos estratégicos são desdobrados em planos de ação, utilizando a ferramenta do $5 \mathrm{~W} 2 \mathrm{H}$, que contempla o orçamento e o acompanhamento da execução das atividades, através de prazos e indicadores.

A avaliação do alinhamento do planejamento estratégico da mantenedora e as unidades operacionais hospitalares ocorre através de dois compartilhamentos anuais, onde estão presentes o grupo de gestão da mantenedora, os membros do conselho de administração e a direção das unidades operacionais hospitalares, sendo que, no primeiro semestre é realizado o acompanhamento das metas e indicadores e no segundo semestre, próximo do final do ano, para revisão das metas e indicadores. De acordo com a entrevista realizada com a Diretora executiva da Associação Alpha, é possível elaborar uma síntese do processo de alinhamento organizacional do planejamento estratégico da mantenedora com as unidades operacionais:

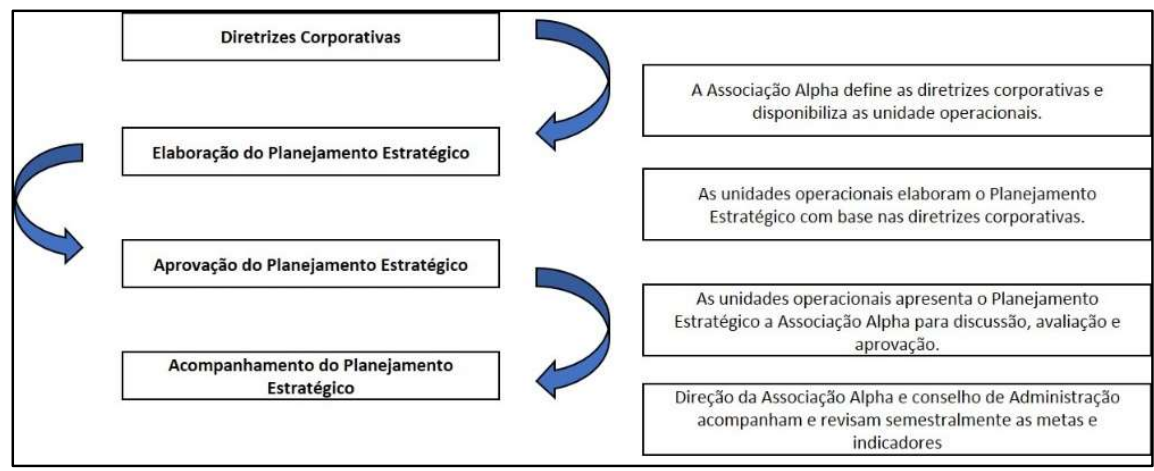

Figura 4: Síntese do alinhamento organizacional entre Associação Alpha e unidades operacionais hospitalares. 
A busca pelo atingimento dos objetivos estratégicos ocorre pela prioridade definida em cada unidade, seguindo as diretrizes da mantenedora, onde se utiliza o balanced scorecard para o acompanhamento dos indicadores prioritários, onde utiliza-se as quatro dimensões da ferramenta. No entanto, pela entrevista com os gestores observa-se que existem dificuldades na definição da ferramenta utilizada e o entendimento dos benefícios da utilização desta ferramenta, e parece não ser utilizada em sua plenitude, ficando lacunas na disseminação para as unidades operacionais hospitalares.

DIRETORA ADMINISTRATIVA - ASSOCIAÇÃO ALPHA - “Nós temos...uma, não saberia dizer se é uma ferramenta, mas é o BSC, que nos auxilia no acompanhamento dos indicadores, aquilo que é prioritário vai para o BSC e é monitorado mensalmente".

Todas as estratégias aprovadas no planejamento estratégico das unidades operacionais hospitalares, com plano de ação elaborado e em conformidade com o orçamento, não necessitam de autorização prévia durante o ano para ser executado, necessitando autorizar junto a Associação Alpha apenas o que não foi previsto.

A maior dificuldade do alinhamento entre o planejamento da mantenedora e das unidades operacionais hospitalares está no cumprimento do orçamento, onde existe uma grande dificuldade na interpretação, elaboração e execução do orçamento anual. $O$ orçamento tende a ser apenas uma formalidade exigida pela mantenedora e obrigatória para as unidades operacionais, ficando o realizado distante dos valores previstos, com valores distorcidos de receita, custo e despesa.

DIRETORA ADMINISTRATIVA - ASSOCIAÇÃO ALPHA- "A dificuldade maior é o extrapolar aquilo que está planejado e orçado, como a ASLB trabalha com um processo de autonomia, as vezes a unidade extrapola o que foi combinado".

O acompanhamento do alinhamento entre Associação Alpha e as unidades operacionais hospitalares é dificultado pelo fator da distância geográfica entre a sede da mantenedora, que é localizada na região metropolitana de Porto Alegre - RS, e as unidades operacionais hospitalares localizadas na região metropolitana e noroeste do Estado do Rio Grande do Sul. Outra lacuna observada é a inexistência de um painel corporativo de indicadores com monitoramento em tempo real ou periódico, para não serem tomadas decisões por parte da mantenedora apenas pelo acompanhamento semestral ou anual destes indicadores.

A mantenedora utiliza um modelo corporativo de 5W2H para acompanhar o andamento da execução dos planos de ação, que é disponibilizado para as unidades operacionais hospitalares, que por sua vez, prestam contas de sua execução. Esse acompanhamento por parte da mantenedora não ocorre de forma proativa e a periodicidade de revisão deve ser melhorada.

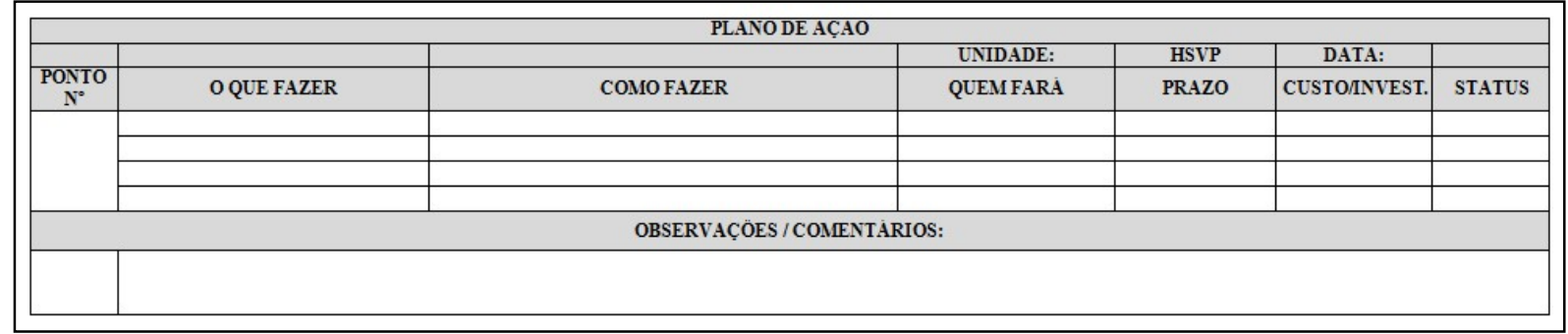

Figura 5: Modelo 5W2H da Associação Alpha. 


\section{Do sistema de acompanhamento e avaliação}

O planejamento estratégico da mantenedora é elaborado com o horizonte de dez anos e revisado anualmente. O acompanhamento dos resultados ocorre através de indicadores de sustentabilidade financeira, cliente e de resultado, dentro do mapa estratégico, que é monitorado mensalmente. Atualmente, o acompanhamento e avaliação dos indicadores ocorre através de planilha eletrônica, onde cada unidade operacional hospitalar alimenta estas planilhas através de seu banco de dados, onde resultam em indicadores controlados pelos gestores. Uma dificuldade exposta, é a inexistência de sistema de informações gerenciais para dar suporte a visualização e acompanhamento dos indicadores, que ficam suscetíveis a critérios diferentes de cálculo e manipulação de informações.

As metas e indicadores passam pela avaliação do conselho de administração da mantenedora, no entanto, o foco é nos resultados, sendo os processos deixados de lado e ficando o acompanhamento sob a responsabilidade das unidades operacionais hospitalares. Nota-se que a mantenedora não visualiza os indicadores de forma sistêmica, ou seja, não tem claro a percepção de que os resultados são impactados pelos processos internos, clientes e funcionários.

Atualmente a Associação Alpha não possui referencial comparativo para os indicadores mensurados e acompanhados nas unidades operacionais hospitalares, ficando a cargo de cada unidade comparar-se a outra instituição que julgar coerente. A mantenedora está trabalhando para buscar um referencial comparativo para utilizar como parâmetro para os indicadores corporativos. A falta de um referencial comparativo definido é uma lacuna na avaliação dos indicadores, fazendo com que, as unidades operacionais hospitalares da Rede se comparem entre si, o que não pode ser considerado ideal para parametrizar todos indicadores, devido a singularidade de cada unidade. Embora, entenda-se que as unidades operacionais hospitalares da rede devam ter sua performance acompanhada e comparadas entre si, porém, não como único parâmetro para melhoria dos processos.

Os avanços resultantes do planejamento estratégico são demonstrados nas reuniões de compartilhamento do alinhamento estratégico que ocorrem semestralmente, com a presença do grupo de gestão da mantenedora, os membros do conselho de administração e a direção das unidades operacionais hospitalares. Não é mensurado quantitativamente os avanços resultantes do planejamento estratégico, esta questão não está clara para a mantenedora, sendo por muitas vezes, avaliada de forma subjetiva.

\section{A estrutura de gestão estratégica das unidades operacionais hospitalares}

\section{Da concepção do modelo de gestão}

Anualmente, o planejamento estratégico das unidades operacionais é revisado e discutido, com a finalidade de analisar o posicionamento estratégico de cada uma das unidades, levando em consideração as peculiaridades de cada uma. Para isso, é utilizada a análise PESTEL, que leva em consideração, fatores políticos, econômicos, sociais, tecnológicos, ecológicos e legais, que impactam em cada unidade de negócio.

A elaboração do planejamento estratégico das unidades operacionais hospitalares segue as 
diretrizes disseminadas pela mantenedora, onde cada unidade elabora o seu planejamento, e em seguida apresenta ao conselho de administração da Associação Alpha para discussão e aprovação. Os gestores relatam que, por vezes, o planejamento estratégico, assim como orçamento, é um tanto quanto figurativo, onde a Associação Alpha não elabora as diretrizes pensando na realidade vivenciada por cada unidade operacional hospitalar.

Reúnem-se para a revisão e elaboração do planejamento estratégico e tático, a alta direção das unidades operacionais hospitalares, onde participam a diretora geral, diretora financeira, diretora de humanização e espiritualidade, diretor executivo e gerências. A diretora geral, diretora financeira e a diretora de humanização e espiritualidade são religiosas, que nem sempre, possuem formação acadêmica voltada para a área de gestão, já o diretor executivo e as demais gerências, são leigos, que possuem formação gerencial e experiência na área de atuação.

Para o planejamento tático, onde são elaborados os planos de ação, a equipe diretiva das unidades operacionais hospitalares conta com a participação dos coordenadores dos serviços, que em sua grande maioria, possuem formação na área de enfermagem, contribuindo muito na área da assistência hospitalar, que é o foco do negócio, no entanto, com pouco domínio de gestão.

O planejamento estratégico, no discurso, está relacionado com o orçamento anual de cada unidade operacional hospitalar, no entanto, ambos são analisados e construídos de forma isolada. O orçamento anual, é construído levando em consideração o realizado do ano anterior, por vezes, tendo caráter figurativo. Não existe um acompanhamento e cobrança efetiva por parte da mantenedora quanto a realização do orçamento anual, sendo que, as unidades operacionais hospitalares não possuem uma gestão criteriosa de custos, principalmente, em se tratando da área hospitalar, onde existem imprevistos diários.

Os principais entraves relacionados ao atual modelo de gestão, está na falta de planejamento prévio das ações, onde as unidades operacionais hospitalares não levam o tempo necessário para pensar estrategicamente as suas ações, o que torna o planejamento estratégico, por vezes, uma obrigação perante a mantenedora, sem contribuir efetivamente para a gestão do negócio.

Outro fator que desencadeia na falta de alinhamento organizacional e endossa as dificuldades encontradas na gestão do negócio, é a falta de integração entre os sistemas informatizados de gestão utilizados pela Associação Alpha e unidades operacionais hospitalares, onde existem três softwares distintos, e que necessita de tratamento manual de dados para operacionalização, o que causa atraso no gerenciamento das informações estratégicas e dificuldades na tomada de decisão.

\section{Do alinhamento organizacional}

A Mantenedora busca um alinhamento estratégico com as unidades operacionais, no entanto, o que é relatado pelos gestores, diverge desta política. Existe um desejo de trabalho conjunto em forma de rede, onde a mantenedora centraliza as estratégias para disseminar nas unidades operacionais, com isso tem-se uma ilusória sensação de dinâmica de trabalho em rede. Segundo os gestores das unidades operacionais hospitalares, muito já se avançou para o trabalho em rede, prova disso, é ações corporativas, principalmente 
focadas em redução de custos.

O alinhamento do planejamento estratégico das unidades operacionais hospitalares com a mantenedora ocorre somente no momento da aprovação do mesmo, e em dois encontros semestrais para discussão, análise e planejamento para o ano seguinte. Dentro das unidades operacionais hospitalares, o planejamento estratégico é revisado anualmente e seus planos de ação acompanhados de acordo com o cronograma previamente estabelecido.

O orçamento das unidades operacionais hospitalares, seguem critérios de aplicação de recursos, projeções de receitas e despesas estabelecidos pela mantenedora. Este é um ponto chave para o não cumprimento do orçamento, pois os valores orçados não condizem com a realidade de cada unidade operacional, por vezes sendo figurativo.

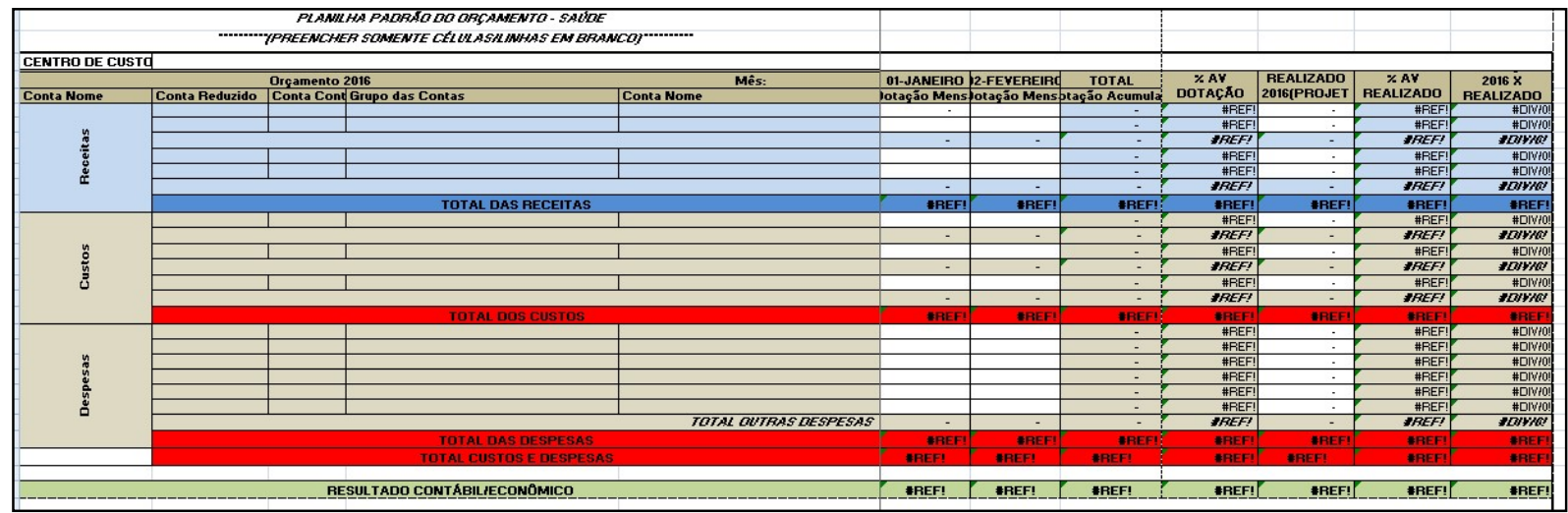

Figura 6: Planilha padrão do orçamento - unidades operacionais hospitalares.

Para atingir os objetivos estratégicos estabelecidos, são elaborados planos de ação, com responsável, custo e prazo estabelecido. Estes valores necessários para o atingimento dos objetivos estratégicos são aprovados previamente pela mantenedora e contemplados no orçamento anual. Ao longo do ano, as unidades operacionais hospitalares avaliam o cumprimento dos prazos estabelecidos e revisando-os quando necessário.

Para o acompanhamento dos resultados do planejamento estratégico não existem parâmetros definidos, e não são utilizados referenciais comparativos. $\mathrm{O}$ atingimento dos objetivos limita-se a conclusão dos planos de ação dentro do prazo estabelecido, no entanto, não é possível mensurar quantitativamente o atingimento dos objetivos propostos.

\section{Sistematização das potencialidades e fragilidades do atual modelo de gestão}

O atual modelo de gestão tem grande importância para a Rede e suas unidades operacionais hospitalares, sendo, apesar de suas limitações, um parâmetro norteador para a gestão do negócio. No desenvolvimento do estudo, através da observação, análise de documentos e entrevistas com gestores, foi possível identificar algumas potencialidade e fragilidades do atual modelo de gestão, que são apresentadas em síntese e explicadas posteriormente. 
Quadro 4: Potencialidades e fragilidades do atual modelo de gestão.

\begin{tabular}{|l|l|}
\hline \multicolumn{1}{|c|}{ Potencialidades do atual sistema de gestão } & \multicolumn{1}{c|}{ Fragilidades do atual sistema de gestão } \\
\hline Solidez da Rede & $\begin{array}{l}\text { Mantenedora com pouco conhecimento da realidade das } \\
\text { unidades operacionais }\end{array}$ \\
\hline $\begin{array}{l}\text { Atuação em diversos segmentos (assistência social, } \\
\text { educação e saúde) }\end{array}$ & Falta de conhecimento técnico dos gestores \\
\hline Presença de religiosas & Distância geográfica entre a Mantenedora e as unidades \\
\hline Possibilidade e esforço para trabalho em Rede & Sistemas de informaçães (softwares de gestão) não padronizados \\
\hline Participação em programas de certificação da gestão & Ausência de referencial comparativo definido para indicadores \\
\hline Benchmarking entre as unidades operacionais & Utilização de apenas algumas perspectivas do BSC \\
\hline $\begin{array}{l}\text { Abertura de dados e comparação de resultado entre } \\
\text { unidades operacionais }\end{array}$ & $\begin{array}{l}\text { Dificuldades na elaboração, acompanhamento e cumprimento do } \\
\text { orçamento anual }\end{array}$ \\
\hline $\begin{array}{l}\text { Utilização do Balanced Scorecard para uma efetiva gestão } \\
\text { por resultados }\end{array}$ & Alinhamento organizacional em estágio inicial \\
\hline
\end{tabular}

Ao analisar o mapa estratégico da mantenedora e das unidades operacionais percebe-se algumas lacunas e fragilidades. A primeira constatação é que os mapas estratégicos não contemplam todas as perspectivas do BSC, precisam ser revistos para incluir a perspectiva de aprendizado e crescimento. Kaplan et al. (1997), complementam dizendo que estas quatro perspectivas devem ser consideradas como um modelo adequado para grande número de organizações, no entanto não precisa ser estático, podendo ser ampliado.

Os mapas estratégicos demonstram falta de alinhamento das estratégias da mantenedora com as unidades operacionais hospitalares, ficando evidenciado na divergência de objetivos em cada perspectiva, sendo possível visualizar alinhamento parcial apenas nos pilares de sustentação do negócio. Os indicadores descritos nos mapas estratégicos demonstram mais uma vez fragilidade no alinhamento entre mantenedora e as unidades operacionais hospitalares, não sendo possível evidenciar critérios de indicadores corporativos e das unidades operacionais, tendo cada unidade operacional hospitalar estratégias distintas.

\section{Proposta de modelo de gestão estratégica com vistas a efetiva gestão por resultados}

Em momentos de dificuldade e incertezas, o planejamento exige flexibilidade e visão sistêmica. Tratando-se de uma rede de hospitais com características singulares, o alinhamento entre a mantenedora e suas unidades operacionais torna-se necessário e não mais um diferencial competitivo. Kaplan et al. (1997) comentam que algumas empresas concentram-se em um único setor, onde existe alinhamento entre as estratégias das unidades e as estratégias corporativas.

A gestão de uma unidade operacional hospitalar, de característica religiosa e filantrópica, é complexa à medida em que envolve equipe multiprofissional, religiosas, leigos, políticas públicas e, principalmente, o direito ao acesso à saúde pela população. Desta forma, sugere-se para a gestão do negócio utilizar indicadores que vão além dos financeiros. A nova forma de gestão, com vistas para uma efetiva gestão por resultado, que o presente estudo propõe à ASLB e suas Unidades Operacionais Hospitalares, é a adoção do Balanced Scorecard, que é, segundo Kaplan et al. (1997) “um sistema de gestão estratégica para administrar a estratégia a longo prazo".

A pesquisa demonstrou que a mantenedora e as unidades operacionais hospitalares têm formalizado um planejamento estratégico, que oportuniza melhorias na sua estruturação, acompanhamento e 
alinhamento organizacional, com necessidade de mudança de foco, com indicadores que busquem uma efetiva gestão por resultados.

Para tanto, sugere-se que a estruturação do novo modelo de gestão seja dividida em três níveis de decisão: estratégico, tático e operacional. A Figura 7 demonstra esta nova estrutura de administração, onde é possível observar com clareza, a alçada de cada nível de decisão dentro do contexto de Rede, que engloba a mantenedora e as unidades operacionais hospitalares.

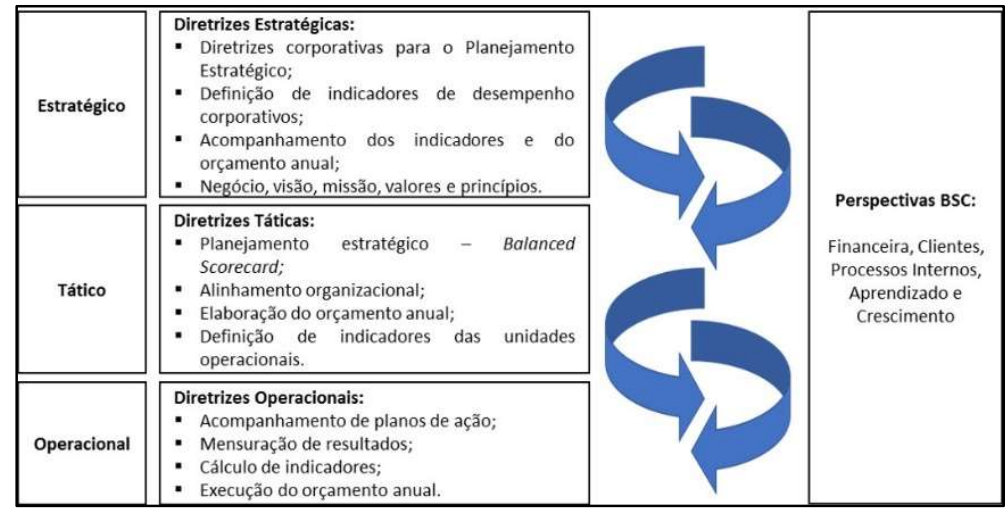

Figura 7: Estrutura de novo modelo de gestão.

\section{CONCLUSÕES}

A gestão Hospitalar é imprescindível para qualquer instituição que busque atendimento em nível de excelência. A gestão de um serviço de Saúde envolve planejar, organizar e coordenar estratégias visando garantir recursos financeiros e humanos para prestar atendimento de saúde qualificado. Para Kaplan e Norton (2000), em se tratando de instituições de assistência médica, o processo de desenvolvimento e implementações de estratégicas torna-se complexo.

O atual modelo de gestão da Associação Alpha apresenta fragilidades na concepção das estratégias corporativas e do planejamento estratégico, grande parte, pela falta de conhecimento do nível estratégico da realidade das unidades operacionais hospitalares. Outra deficiência e em relação ao orçamento anual, que não tem relacionamento direto com as estratégias do planejamento estratégico e possui acompanhamento deficitário. Quanto ao alinhamento organizacional, percebeu-se que as diretrizes corporativas convergem para o alinhamento com as unidades operacionais hospitalares, seguindo a lógica da definição das diretrizes corporativas, elaboração, aprovação e acompanhamento do planejamento estratégico. Na prática observou-se que existe um descompasso neste alinhamento, onde é evidenciado com clareza apenas nos pilares de sustentação dos mapas estratégicos, que não são seguidos na sua integralidade.

O presente estudo propõe a Associação Alpha e suas unidades operacionais hospitalares como nova forma de gestão, com vistas para uma efetiva gestão por resultados, a adoção do Balanced Scorecard, segundo Kaplan et al. (1997; 2000; 2006) e sua estruturação e condução em três níveis de decisão: estratégico, tático e operacional. Por fim é válido registar que a pesquisa teve o foco na visão dos gestores da Associação Alpha e das unidades operacionais hospitalares, e que no decorrer da pesquisa, devido a reorganização do quadro funcional da Rede para enfrentamento da crise da área da saúde, houve uma 
redução do número de gestores entrevistados. Estes aspectos constituem em uma limitação para o estudo. Pela relevância da pesquisa, acredita-se ser relevante ampliar este estudo para as unidades operacionais dos segmentos da educação e assistência social pertencentes a Associação Alpha, fortalecendo o trabalho em Rede.

\section{REFERÊNCIAS}

ALLEVATO, R. C. G.. O Balanced Scorecard como modelo de gestão estratégica integrada. Proposta de uma metodologia de utilização em hospitais com base no estudo de caso do Hospital Monte Sinai de Juíz de Fora. Dissertação (Mestrado em Sistemas de Gestão) Universidade Federal Fluminense, Niterói, 2007.

ANSOFF, I. H.; MCDONNELL, E. J.. Implantando a administração estratégica. 2 ed. São Paulo: Atlas, 1993.

BARROS, L. A. M.. Alinhamento estratégico. Tese (Doutorado em Administração) - Universidade de São Paulo, São Paulo, 2007.

BETHLEM, A.. Estratégia empresarial: conceitos, processo e administração estratégica. 3 ed. São Paulo: Atlas, 2001.

CALHAU, A. R. L.. Concepção de um Sistema de Balanced Scorecard para o Serviço de Traumatologia do Hospital Garcia de Orta. Dissertação (Mestrado em Engenharia Biomédica) - Universidade Técnica de Lisboa, Lisboa, 2009.

CARVALHO, C. E.; ROSSETO, C. R.; VIANNA, S. L. G. Determinismo e voluntarismo na adaptação estratégica: o caso de uma empresa de varejo. Revista de Administração e Contabilidade da Unisinos, v.8, n.4, p.286-299, 2011. DOI: http://dx.doi.org/10.4013/base.2011.84.02

CARVALHO, F. M.; DIAS, L. N. S.; PROCHNIK, V.. A utilização do Balanced Scorecard em hospitais: o caso do Hospital Nove de Julho. In: CONGRESSO INTERNACIONAL DE CUSTOS, 9. Anais. Florianópolis, 2005.

CERETTA, P. S.; QUADROS, C. J.. Implementação do Balanced Scorecard: um caso prático. Revista Eletrônica de Administração, v.9, n.4, p.1-18, 2003.

COELHO, M.. A essência da administração: conceitos introdutórios. São Paulo: Saraiva, 2008.

CUNHA, J. A. C.; CORRÊA, H. L.. Avaliação de desempenho organizacional: um estudo aplicado em hospitais filantrópicos. Revista de Administração de Empresas, v.53, n.5, p.485-499, 2013.

DEMO, P.. Metodologia científica em ciências sociais. São Paulo: Atlas, 1996

FILGUEIRAS, A. A.; BARROS, L. P. S.; GOMES, J. S.. O processo de implantação do Balanced Scorecard em uma empresa estatal brasileira: o caso Petrobras. Revista de Gestão, v.17, n.1, p.45-57, 2010.

FLORES, E. L.; FACHINELLI, A. C.; GIACOMELLO, C. P.. O alinhamento do pensamento estratégico: o balanced scorecard como condutor do processo na caixa econômica federal. Global Manager, v.15, p.65-86, 2008.
GIL, Antônio C. Métodos e técnicas de pesquisa social. 5 ed São Paulo: Atlas, 1999.

HENDERSON, J. C.; VENKATRAMAN, N.. Strategic alignment: Leveraging information technology for transforming organizations. IBM System Journal, v.32, n.1, p.198-220, 1993.

HREBINIAK, L. G.; JOYCE, W. F.. Organizational adaptation: strategic choice and environmental determinism. Administrative Science Quarterly, v.30, p.336-349, 1985. DOI: http://dx.doi.org/10.2307/2392666

KAPLAN, R. S.; NORTON, D. P.. The balanced scorecard: measures that drive performance. Harvard Business Review, v.70, n.1, p.71-79, 1992

KAPLAN, R. S.; NORTON, D. P.. A estratégia em ação Balanced Scorecard. Rio de Janeiro: Elsevier, 1997

KAPLAN, R. S.; NORTON, D. P.. Organização orientada para a estratégia: como as empresas que adotam o balanced scorecard prosperam no novo ambiente de negócios. 4 ed Rio de Janeiro: Campus, 2000.

KAPLAN, R. S.; NORTON, D. P.. Alinhamento: utilizando o balanced scorecard para criar sinergias corporativas. 10 ed. Rio de Janeiro: Elsevier, 2006

LABOVITZ, G.; ROSANSKY, V.. The power of alignment: how great companies stay centered and accomplish extraordinary things. Washington: John Wiley e Sons, 1997.

LIMA, C. R. M.; SOARES, T. C.; LIMA, M. A. Balanced Scorecard em instituições de ensino superior: uma análise das perspectivas. Revista Eletrônica de Estratégia e Negócios, Florianópolis, v.4, n.1, p.183-205, 2011.

LIMA, S. M. L.; PORTELA, M. C.; UGÁ, M. A. D.; BARBOSA, P. R.; GERSCHMAN, S.; VASCONCELLOS, M. M.. Hospitais filantrópicos e a operação de planos de saúde próprios no Brasil. Revista de Saúde Pública, v.41, n.1, p.116-123, 2007.

MACHADO, M. J. C. V.. Balanced Scorecard: an empirical study of small and medium size enterprises. Revista Brasileira de Gestão de Negócios, v.15, n.46, p.129-148, 2013.

MENEZES, M. T.; QUEIROZ, D. G. B. S.; BRITO, B. B; JOSÉ, A. S. D.. Implantação do balanced scorecard: O caso do departamento de logística da CST. Revista Tecnologia em Metalurgia e Materiais, v.3, n.1, p.7-12, 2006. DOI: http://dx.doi.org/10.4322/tmm.00301002

MILES, R. E.; SNOW, C. C.. Fit, Failure and the hall of fame. California Management Review, v.26, n.3, 1984 
MINAYO, C. S.. Pesquisa Social: Teoria, método e criatividade. 27 ed. Petrópolis: Vozes, 2008.

MINTZBERG, H.; AHLSTRAND, B.; LAMPEL, J.. Safari de estratégia: um roteiro pela selva do planejamento estratégico. 2 ed. Porto Alegre: Bookman, 2010.

MINTZBERG, H.; LAMPEL, J.; QUINN, J. B.; GHOSHAL, S.. 0 processo da estratégia: conceitos, contextos e casos selecionados. 4 ed. Porto Alegre: Bookman, 2006.

MOTTA, P. R.. Transformação organizacional: a teoria e a prática de inovar. 4 ed. Rio de Janeiro: Qualitymark, 2001.

PESSOA, R. M.; SILVEIRA, C. S.. Alinhamento estratégico na secretaria de Estado de saúde de Minas Gerais: a área meio no contexto da gestão para resultados. In: ENCONTRO ANUAL DA ANPAD, 35. Anais. Rio de Janeiro, 2011.

PORTER, M. E.. How competitive forces shape strategy. Harvard Business Review, p.137-145, 1979.

PORTER, M. E.. Vantagem competitiva: criando e sustentando um desempenho superior. Rio de Janeiro: Campus, 1992.

PORTER, M. E.. Competição: estratégias competitivas essenciais. Rio de Janeiro: Campus, 1999.

PORTER, M. E.; MILLAR, V. E.. How information gives you competitive advantage. Harvard Business Review, v.63, p.149-160, 1985.

PRIETO, V. C.; CARVALHO, M. M.. Diagnóstico de alinhamento estratégico: estudo de múltiplos casos. In: ENCONTRO NAC. DE ENG. DE PRODUÇÃO, 14. Anais. 2004.

SANTOS, A. M.. Balanced Scorecard como ferramenta de gestão aplicada a uma unidade hospitalar privada. Dissertação (Mestrado em Engenharia da Produção) Universidade Federal do Rio Grande do Norte, Natal, 2001.

SAUSEN, J. O.. Mudança e adaptação estratégica no contexto da competitividade e do desenvolvimento regional. In: TENÓRIO, F. G.. Gestão social e gestão estratégica: experiências em desenvolvimento territorial. 2 ed. 2013. p.237-369.

SENFF, C. O.; COMPAGNONI, U. M.; BENDLIN, L.. Mensuração do grau de alinhamento estratégico: um estudo de caso. Revista Brasileira de Estratégia, v.7, n.2, p.120-136, 2014.

STEPANNOVICH, P. L.; MUELLER, J. D.. Mapping Strategic Consensus. Journal of Business and Management, Fort Collins, v.8, p.147-164, 2002.

TRIVIÑOS, A. N. S.. Introdução à pesquisa em ciências sociais: a pesquisa qualitativa em educação. 11 ed. São Paulo: Atlas, 1987.

VERGARA, S. C.. Projetos e relatórios de pesquisa em administração. 5 ed. São Paulo: Atlas, 2009.

WHITTINGTON, R.. O que é estratégia. São Paulo: Pioneira, 2002.

YIN, R. K.. Estudo de caso: planejamento e método. Porto Alegre: Bookmann, 2003.

A CBPC - Companhia Brasileira de Produção Científica (CNPJ: 11.221.422/0001-03) detém os direitos materiais desta publicação. Os direitos referem-se à publicação do trabalho em qualquer parte do mundo, incluindo os direitos às renovações, expansões e disseminações da contribuição, bem como outros direitos subsidiários. Todos os trabalhos publicados eletronicamente poderão posteriormente ser publicados em coletâneas impressas sob coordenação da Sustenere Publishing, da Companhia Brasileira de Produção Científica e seus parceiros autorizados. Os (as) autores (as) preservam os direitos autorais, mas não têm permissão para a publicação da contribuição em outro meio, impresso ou digital, em português ou em tradução. 